\title{
AnI open Dentists' practice patterns regarding caries prevention: results from a dental practice-based research network
}

\author{
Yoko Yokoyama, ${ }^{1,2}$ Naoki Kakudate, ${ }^{3}$ Futoshi Sumida, ${ }^{4}$ Yuki Matsumoto, ${ }^{5}$ \\ Gregg H Gilbert, ${ }^{6}$ Valeria V Gordan ${ }^{7}$
}

To cite: Yokoyama $Y$, Kakudate N, Sumida F, et al. Dentists' practice patterns regarding caries prevention: results from a dental practice-based research network. BMJ Open 2013;3: e003227. doi:10.1136/ bmjopen-2013-003227

- Prepublication history for this paper is available online. To view these files please visit the journal online (http://dx.doi.org/10.1136/ bmjopen-2013-003227).

Received 14 May 2013 Revised 2 August 2013 Accepted 9 August 2013

\footnotetext{
${ }^{1}$ Japan Society for the Promotion of Science ${ }^{2}$ Department of Preventive Medicine and Epidemiology, National Cerebral and Cardiovascular Center, Suita, Osaka, Japan

${ }^{3}$ Educational Cooperation Center, Kyushu Dental University, Kitakyushu, Fukuoka, Japan

${ }^{4}$ Mikami Dental and Orthodontics Clinic, Tomakomai, Hokkaido, Japan ${ }^{5}$ Matsumoto Dental Clinic, Okazaki, Aichi, Japan

${ }^{6}$ Department of Clinical and Community Sciences, School of Dentistry, University of Alabama at Birmingham, Birmingham, Alabama, USA ${ }^{7}$ Department of Restorative Dental Sciences, University of Florida College of Dentistry, Gainesville, Florida, USA
}

Correspondence to Yoko Yokoyama; yyokoyama-kyt@umin.ac.jp

\section{ABSTRACT}

Objective: The purposes of this study were to (1) quantify dentists' practice patterns regarding caries prevention and (2) test the hypothesis that certain dentists' characteristics are associated with these practice patterns.

Design: The study used a cross-sectional study design consisting of a questionnaire survey.

Participants: The study queried dentists who worked in outpatient dental practices who were affiliated with the Dental Practice-Based Research Network Japan, which seeks to engage dentists in investigating research questions and sharing experiences and expertise $(n=282)$.

Measurement: Dentists were asked about their practice patterns regarding caries preventive dentistry. Background data on patients, practice and dentist were also collected.

Results: $38 \%$ of dentists $(n=72)$ provided individualised caries prevention to more than $50 \%$ of their patients. Overall, $10 \%$ of the time in daily practice was spent on caries preventive dentistry. Dentists who provided individualised caries prevention to more than $50 \%$ of their patients spent significantly more time on preventive care and less time on removable prosthetics treatment, compared to dentists who did not provide individualised caries prevention. Additionally, they provided oral hygiene instruction, patient education, fluoride recommendations, intraoral photographs taken and diet counselling to their patients significantly more often than dentists who did not provide individualised caries prevention. Multiple logistic regression analysis suggested that the percentage of patients interested in caries prevention and the percentage of patients who received hygiene instruction, were both associated with the percentage of patients who receive individualised caries prevention.

Conclusions: We identified substantial variation in dentists' practice patterns regarding preventive dentistry. Individualised caries prevention was significantly related to provision of other preventive services and to having a higher percentage of patients interested in caries prevention, but not to the dentist's belief about the effectiveness of caries risk assessment. (Clinicaltrials.gov registration number NCT01 680 848).

\section{ARTICLE SUMMARY}

Strengths and limitations of this study

- To our knowledge, this is the first study to clarify dentists' practice patterns regarding caries prevention in Japan has substantial variation in the Dental Practice-Based Research Network.

- This study suggested possible reasons for the variation of practice patterns regarding caries prevention.

- This study has relatively wide diversity of participants, with respondents from all seven regions in Japan. Given the cross-sectional nature of the study, causative relationships between factors and the provision of individualised caries prevention were difficult to assess.

\section{INTRODUCTION}

Dental caries is a largely preventable disease, ${ }^{1-3}$ but it continues to affect $60-90 \%$ of school children and almost $100 \%$ of adults, constituting the most common chronic disease among children and adolescents. ${ }^{4}{ }^{5}$ Oral health is essential to general health and optimal quality of life and the high prevalence of dental caries highlights the importance of public health approaches to its prevention. ${ }^{5}$ According to Zero et $a t^{6}$, dental caries is a dynamic dietomicrobial disease involving cycles of demineralisation and remineralisation. The early stages of this process are reversible by modifying or eliminating aetiological factors (such as plaque biofilm and diet) and increasing protective factors (such as fluoride exposure and salivary flow). ${ }^{6}$ Axelsson $e t a l^{7} 8$ noted that improved selfperformed oral hygiene, the daily use of fluoridated dentifrice, regularly repeated professional tooth cleanings and plaque control effectively prevented the recurrence of dental caries. ${ }^{7} 8$ Caries risk assessment is the first step in preventive treatment. ${ }^{9}$ Risk assessment is the determination of the person's 
probability of developing new carious lesions during a specific time period and the probability of a change in the size or activity of existing lesions across time..$^{2} 1011$ Our previous studies revealed that dentists' perception of each potential caries risk factor and the administration of diet counselling varied between dentists. ${ }^{12}{ }^{13}$ However, dentists' practice patterns regarding caries prevention and factors that affect these patterns remain unclear. The recent establishment of the Dental Practice-Based Research Network Japan (JDPBRN) created an opportunity for international comparisons. JDPBRN is a consortium of dental practices with a broad representation of practice types, treatment philosophies and patient populations and it has a shared mission with the DPBRN, ${ }^{14}$ now called the National DPBRN (http:// NationalDentalPBRN.org). The network regions of the JDPBRN represent all seven districts in Japan (Hokkaido, Tohoku, Kanto, Chubu, Kansai, Chugoku-Shikoku and Kyushu). The studies conducted in the USA and Japan shared the same purpose of clarifying practice patterns regarding caries diagnosis and treatment.

The purposes of this study were to (1) quantify dentists' practice patterns regarding caries preventive dentistry and (2) test the hypothesis that certain dentists' characteristics are associated with these practice patterns.

\section{MATERIALS AND METHODS}

\section{Study design}

We conducted a cross-sectional study consisting of a questionnaire survey, which was administered in Japan between May 2011 and February 2012. ${ }^{12}$ This study followed the World Association's Declaration of Helsinki. All participants provided written informed consent prior to participation. We used the same questionnaire that was used in the US DPBRN study 'Assessment of Caries Diagnosis and Caries Treatment' ${ }^{15}$ and the 'DPBRN Enrollment Questionnaire'. ${ }^{16}$ Four dentists and clinical epidemiologists collaboratively translated these questionnaires into Japanese. The translated version of these questionnaires is available at http:// www.dentalpbrn.org/uploadeddocs/Study\%201(Japanese \%20Version.pdf). (Original English version: http:// nationaldentalpbrn.org/pdf/Study\%201\%20questionnaire \%20FINAL\%20after\%20pre-testing\%20021306.pdf). The questionnaires used in this study were validated by expert consultation and focus groups on potential subjects. ${ }^{17}$ Dentists were asked about their practice patterns regarding caries preventive treatment. Background data on patients, practice and participating dentists were also requested.

Questionnaires were distributed, answered and returned through the method described in the previous study. ${ }^{12} 1518$

\section{Participants}

We queried dentists working in outpatient dental practices who were affiliated with JDPBRN ( $n=282)$. Participants who indicated that they perform restorative dentistry at their practice were recruited from the JDPBRN website and mailings.
Variables

Dentists' practice patterns regarding individualised caries preventive dentistry

Practice patterns regarding individualised caries preventive regimens were measured with the following question: for what per cent of patients do you administer individualised caries preventive treatment specifically for their needs?

Items used to measure practice patterns regarding time spent doing prevention-related care and percentage of patients who receive specific dental services

Practice patterns regarding time spent doing preventionrelated care and the percentage of patients who received specific dental services was measured using the questions listed in table 1.

\section{Variable selection}

To identify the characteristics of the dentist, patient and practice that were associated with the use of individualised caries prevention, theoretical models were discussed and identified in accordance with previous studies. ${ }^{12} 151920$ In addition, explanatory variables were extracted, consisting of four categories shown in table 1 .

\section{Statistical analysis}

Description and comparison of practice patterns by the use of individualised caries prevention

We examined the relationship between dental practice patterns and the use of individualised caries prevention. $\chi^{2}$ tests were performed to assess the association between practice patterns and the use of individualised caries prevention.

The use of individualised caries prevention was categorised dichotomously: 'less preventive' (1-49\%) and 'more preventive' (50-100\%), according to a previous study. ${ }^{9}$ To compare our data with the US data, we calculated the mean percentages of patients who received individualised caries prevention according to a previous study. ${ }^{9}$

\section{Factors affecting the decision to provide individualised caries} prevention

Descriptive analysis was conducted through univariate regression analysis for explanatory variables associated with dentists' practice patterns of individualised caries prevention. Subsequently, multiple logistic regression analysis was conducted to examine the relationship between explanatory variables and the prevalence of patients receiving individualised caries prevention. Odds ratios (ORs) and 95\% confidential intervals (CIs) were calculated. All statistical analyses were performed with STATA/SE (V.10; STATA Corporation, College Station, Texas, USA). Statistical significance was set at $\mathrm{p}<0.05$.

\section{RESULTS}

\section{Demographic information of participants}

Questionnaires were distributed to 282 dentists and valid responses were collected from 189 (67\%). The 
Table 1 Outcomes and explanatory variables

\begin{tabular}{|c|c|c|}
\hline Variables & Details & \\
\hline $\begin{array}{l}\text { Percentage of patient } \\
\text { contact time }\end{array}$ & $\begin{array}{l}\text { What percentage of patient contact time do } \\
\text { you (excluding your hygienist or other office } \\
\text { staff) spend in a typical month performing the } \\
\text { following procedures? If you always refer } \\
\text { these procedures to other practitioners, please } \\
\text { record } 0 \%\end{array}$ & $\begin{array}{l}\text { (1) Non-implant restorative (amalgams, } \\
\text { composites, crowns, bridges, posts, foundations, } \\
\text { etc); (2) implants (prosthetic and surgical } \\
\text { procedures for implants); (3) removable } \\
\text { prosthetics (full and partial dentures); (4) } \\
\text { extractions (surgical and non-surgical); (5) } \\
\text { periodontal therapy (surgical and non-surgical; } \\
\text { includes scaling/root planing that you personally } \\
\text { do); (6) endodontic therapy (root canals and endo } \\
\text { surgery); (7) other (sealants, periodic and } \\
\text { hygiene examinations, preventive dentistry, } \\
\text { diagnostic or other; please specify) }\end{array}$ \\
\hline $\begin{array}{l}\text { Percentage of patients } \\
\text { who received specific } \\
\text { dental services }\end{array}$ & $\begin{array}{l}\text { On what percentage of patients do you or } \\
\text { your staff perform the following services at } \\
\text { some time while they are patients in your } \\
\text { practice }\end{array}$ & $\begin{array}{l}\text { (1) Diet counseling; (2) blood pressure screening, } \\
\text { (3) oral cancer screening examination, (4) oral } \\
\text { hygiene instruction, (5) in-office fluoride } \\
\text { application, (6) fluoride gel/rinse prescribed or } \\
\text { recommended for home use, (7) patient } \\
\text { education from written pamphlets, (8) patient } \\
\text { education from videos or slides, (9) intraoral } \\
\text { photographs taken (conventional, non-video } \\
\text { photography), (10) intraoral video images taken } \\
\text { (usually performed with fiberoptic), (11) in-office } \\
\text { whitening (usually performed with hydrogen } \\
\text { peroxide), (12) at-home whitening (usually } \\
\text { performed with carbamide peroxide) }\end{array}$ \\
\hline \multirow[t]{3}{*}{ Explanatory variables } & $\begin{array}{l}\text { (1) Dentists' individual characteristics } \\
\text { (2) Practice setting }\end{array}$ & $\begin{array}{l}\text { Years since graduation from dental school, } \\
\text { gender and efficacy of caries risk assessment } \\
\text { Type of practice, practice busyness and city } \\
\text { population (government ordinance-designated } \\
\text { city with population over } 700000 \text { or not) }\end{array}$ \\
\hline & (3) Patients' characteristics & $\begin{array}{l}\text { Percentage of patients interested in caries } \\
\text { prevention, patient age distribution and per cent } \\
\text { of patients who self-pay }\end{array}$ \\
\hline & (4) Procedure-related characteristics & $\begin{array}{l}\text { Whether caries risk is assessed as a routine part } \\
\text { of treatment planning and the percentage of } \\
\text { patients receiving hygiene instruction } \\
\text { Percentage of patients who receive individualised } \\
\text { caries prevention }\end{array}$ \\
\hline
\end{tabular}

demographic characteristics of the study participants are shown in table 2. ${ }^{12} 13$ The mean number of years $( \pm$ SD) elapsed since graduation from dental school was $18.5 \pm 9.9$ and the participants were predominantly men $(n=154$, $82 \%)$. With regard to practice setting, $40 \%(n=76)$ of practices were established in government ordinancedesignated cities of over 700000 . The percentage of dentists who performed caries risk assessment as a routine part of treatment planning was $26 \%(n=49)$. The percentage of dentists who agreed that caries risk assessment is effective was $67 \%(n=127)$.

\section{Dentists' practice patterns according to provision of individualised caries prevention}

Seventy-two participants $(38 \%)$ answered that $50 \%$ or more of their patients received individualised caries prevention (ie, were 'more preventive'). Eleven participants
$(6 \%)$ answered that $100 \%$ of their patients received individualised caries prevention (figure 1).

Table 3 shows the practice patterns of dental procedures and the differences of practice patterns by use of individualised caries prevention. Participants spent $29 \%$ of their time on non-implant restorative, $19 \%$ on endodontic therapy and $18 \%$ on removable prosthetics. Participants spent $10 \%$ of their time on preventionrelated care. Participants who were 'more preventive' $(n=72)$ spent significantly more time on preventive dentistry $(\mathrm{p}=0.0007)$ and less time on removable prosthetics $(\mathrm{p}=0.0159)$.

Table 4 shows the relation among certain procedures performed in general dental practice and the percentage of time that patients receive prevention-related care. The mean percentage of patients who receive oral hygiene instruction was $67 \%$, while $37 \%$ received patient 


\section{Table 2 Summary of dentists', practices' and patients' characteristics and certain dental procedures performed ${ }^{12} 13$}

\begin{tabular}{|c|c|}
\hline \multicolumn{2}{|l|}{ Dentist's individual characteristics } \\
\hline Years since graduation from dental school (year)* $(n=185)$ & $18.5 \pm 9.9$ \\
\hline Gender (male), $n(\%)(n=187)$ & $154(82)$ \\
\hline \multicolumn{2}{|l|}{ Belief about the effectiveness of caries risk assessment, $n(\%)(n=189)$} \\
\hline Agree & $127(67)$ \\
\hline Disagree or neutral & $62(33)$ \\
\hline \multicolumn{2}{|l|}{ Practice setting } \\
\hline \multicolumn{2}{|l|}{ Type of practice, $n(\%)(n=182)$} \\
\hline Employed by another dentist & $77(41)$ \\
\hline Self-employed without partners and without sharing of income, costs or office space & $105(56)$ \\
\hline \multicolumn{2}{|l|}{ Practice busyness, $n(\%)(n=181)$} \\
\hline Too busy to treat all people requesting appointments & $19(11)$ \\
\hline Provided care to all, but the practice was overburdened & $72(40)$ \\
\hline Provided care to all, but the practice was not overburdened & 59 (33) \\
\hline Not busy enough & $31(17)$ \\
\hline City population (government ordinance-designated city), $n(\%)(n=189)$ & $76(40)$ \\
\hline \multicolumn{2}{|l|}{ Patients' characteristics } \\
\hline \multicolumn{2}{|l|}{ Percentage of patients interested in caries prevention, $n(\%)(n=189)$} \\
\hline 0 (none) & $16(8)$ \\
\hline $1-24$ & $80(42)$ \\
\hline $25-49$ & $38(20)$ \\
\hline $50-74$ & $46(24)$ \\
\hline 75-99 & $8(4)$ \\
\hline 100 & $1(1)$ \\
\hline \multicolumn{2}{|l|}{ Patient age distribution (years)* } \\
\hline $1-18(\%)(n=183)$ & $16.1 \pm 13.2$ \\
\hline $19-44(\%)(n=188)$ & $24.8 \pm 11.0$ \\
\hline $45-64(\%)(n=183)$ & $30.4 \pm 11.2$ \\
\hline $65+(\%)(n=183)$ & $28.5 \pm 17.4$ \\
\hline Percent of patients who self-pay $(\%)^{*}(n=183)$ & $8.6 \pm 16.6$ \\
\hline \multicolumn{2}{|l|}{ Dental procedure characteristics } \\
\hline \multicolumn{2}{|l|}{ Percentages of patients who receive individualised caries prevention, $n(\%)(n=189)$} \\
\hline 0 (none) & $9(5)$ \\
\hline $1-24$ & $68(36)$ \\
\hline $25-49$ & $40(21)$ \\
\hline $50-74$ & $37(20)$ \\
\hline 75-99 & $24(13)$ \\
\hline 100 & $11(6)$ \\
\hline Caries risk is assessed as a routine part of treatment planning, $n(\%)(n=189)$ & $49(26)$ \\
\hline Percentage of patients who received hygiene instruction $(\%)^{\star}(n=183)$ & $67.3 \pm 34.8$ \\
\hline
\end{tabular}

${ }^{*}$ Mean \pm SD.

education from written pamphlets. Participants who were 'more preventive' ( $\mathrm{n}=72$ ) administered significantly more oral hygiene instruction $(\mathrm{p}<0.0001)$, gave written pamphlets $(\mathrm{p}<0.0001)$, either prescribed fluoride gels $/$ rinses or recommended for home use $(p<0.0001)$, had patient education available from videos or slides $(\mathrm{p}=0.0011)$, obtained intraoral photographs $(\mathrm{p}=0.0021)$, had in-office fluoride applications $(\mathrm{p}<0.0001)$ and provided diet counselling $(\mathrm{p}=0.0004)$.

\section{Factors associated with providing individualised caries} prevention

The results of multiple logistic regression analysis are shown in table 5 . Two factors were significantly associated with whether or not the practitioner reported providing individualised caries prevention to $50 \%$ of patients or more. The ORs (95\% CIs) were as follows: the percentage of patients interested in caries prevention, 5.81 (3.15 to 10.70$)$; and the percentage of patients who received hygiene instruction, 1.02 (1.01 to 1.04$)$.

\section{DISCUSSION}

Seventy-two participants $(38 \%)$ answered that the percentage of patients who received individualised caries prevention was $50 \%$ or more ('more preventive'). Overall, $10 \%$ of the time in daily practice was spent on prevention-related care. Dentists who provided individualised caries prevention to $50 \%$ or more of their patients spent significantly more time on preventive care and provided less removable prosthetics treatment than 
Figure 1 Distribution of the percentages of patients who receive individualised caries prevention, n. Seventy-two participants (38\%) answered that $50 \%$ or more of their patients received individualised caries prevention. Eleven participants $(6 \%)$ answered that $100 \%$ of their patients received individualised caries prevention.

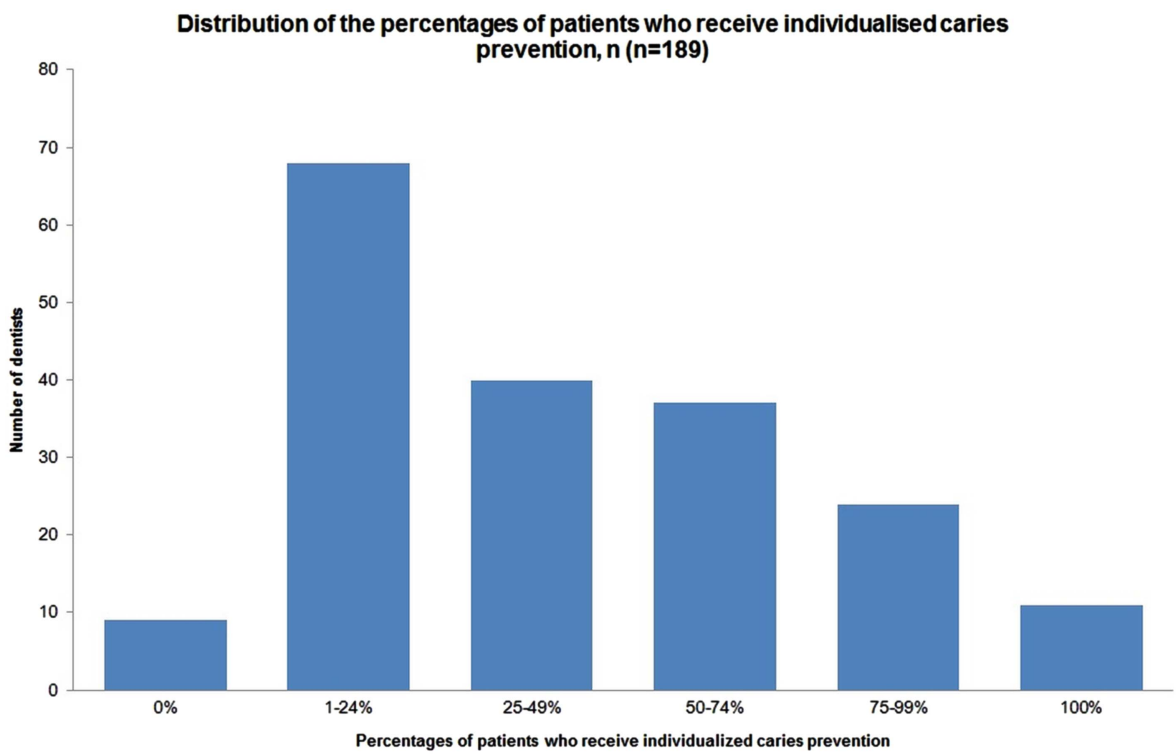

those who did not. Additionally, they provided oral hygiene instruction, patient education, fluoride recommendations and diet counselling to their patients significantly more often than dentists who provided individualised caries prevention to less than $50 \%$ of their patients. The results of the multiple logistic regression analysis suggested that several variables were associated with whether or not dentists provide individualised caries prevention to $50 \%$ or more of their patients. Specifically, the percentage of patients interested in caries prevention and the percentage of patients who received hygiene instruction were significantly associated with high percentages of patients who receive individualised caries prevention.

According to the results of the same questionnaire survey by the US DPBRN, $52 \%$ of patients received individualised caries prevention. ${ }^{9} 21$ The results of this study possibly suggest that dentists in the DPBRN and JDPBRN $(41.3 \%)$ have similar tendencies in providing individualised caries prevention, but the proportion was lower in Japan than in the USA. Additionally, dentists spent $10 \%$ of their time on prevention-related care in

Table 3 Percentage of patient contact time spent doing certain procedures in a typical month, overall and by the percentage of patients who receive individualised caries prevention

\begin{tabular}{|c|c|c|c|c|c|}
\hline \multirow[b]{2}{*}{ Variable } & \multirow[b]{2}{*}{ All* } & \multicolumn{2}{|c|}{$\begin{array}{l}\text { Individualised caries } \\
\text { prevention }\end{array}$} & \multirow[b]{2}{*}{$\begin{array}{l}\text { Differencet (more } \\
\text { preventive-less } \\
\text { preventive) }\end{array}$} & \multirow[b]{2}{*}{ p Value } \\
\hline & & $\begin{array}{l}0-49 \% \%^{*} \text { (less } \\
\text { preventive) }\end{array}$ & $\begin{array}{l}50-100 \% * \\
\text { (more } \\
\text { preventive) }\end{array}$ & & \\
\hline $\begin{array}{l}\text { Prevention-related care (sealants, periodic } \\
\text { and hygiene examinations, preventive } \\
\text { dentistry, diagnostic or other; } \mathrm{N}=183 \text { ) }\end{array}$ & 9.5 (11.2) & $7.4(6.6)$ & $13.1(15.8)$ & $5.8(1.7)$ & 0.0007 \\
\hline $\begin{array}{l}\text { Non-implant restorative (amalgams, } \\
\text { composites, crowns, bridges, posts, } \\
\text { foundations, etc; } N=183 \text { ) }\end{array}$ & $28.7(14.2)$ & $27.7(13.1)$ & $30.6(15.9)$ & $2.9(2.2)$ & 0.1813 \\
\hline $\begin{array}{l}\text { Implants (prosthetic and surgical } \\
\text { procedures for implants; } N=183 \text { ) }\end{array}$ & $2.8(7.5)$ & $2.2(7.0)$ & $3.9(8.2)$ & $1.6(1.1)$ & 0.1544 \\
\hline $\begin{array}{l}\text { Periodontal therapy (surgical and } \\
\text { non-surgical; includes scaling/root } \\
\text { planning that you personally do; } \mathrm{N}=183 \text { ) }\end{array}$ & $12.9(10.1)$ & $13.2(10.5)$ & $12.5(9.4)$ & $-0.7(1.5)$ & 0.6377 \\
\hline $\begin{array}{l}\text { Extractions (surgical and non-surgical; } \\
\mathrm{N}=183 \text { ) }\end{array}$ & $8.8(6.2)$ & $9.3(7.2)$ & $7.9(4.1)$ & $-1.5(0.9)$ & 0.1274 \\
\hline $\begin{array}{l}\text { Endodontic therapy (root canals and } \\
\text { endosurgery; } N=183 \text { ) }\end{array}$ & $19.2(11.0)$ & $20.3(12.1)$ & $17.4(8.6)$ & $-2.9(1.7)$ & 0.0856 \\
\hline $\begin{array}{l}\text { Removable prosthetics (full and partial } \\
\text { dentures; } N=183 \text { ) }\end{array}$ & $17.6(11.9)$ & $19.2(13.0)$ & $14.8(9.3)$ & $-4.4(1.8)$ & 0.0159 \\
\hline
\end{tabular}


Table 4 Dentists' reports of the percentage of patients who receive the procedure at some time in their practice, overall and by the percentage of patients in the practice who receive individualised caries prevention

\begin{tabular}{|c|c|c|c|c|c|}
\hline \multirow[b]{2}{*}{ Variable } & \multirow[b]{2}{*}{ All* } & \multicolumn{2}{|c|}{ Individualised caries prevention } & \multirow{2}{*}{$\begin{array}{l}\text { Differencet (more } \\
\text { preventive-less } \\
\text { preventive) }\end{array}$} & \multirow[b]{2}{*}{ p Value } \\
\hline & & $\begin{array}{l}0-49 \% \%^{*} \text { (less } \\
\text { preventive) }\end{array}$ & $\begin{array}{l}50-100 \% * \text { (more } \\
\text { preventive) }\end{array}$ & & \\
\hline Oral hygiene instruction $(\mathrm{N}=183)$ & $67.3(34.8)$ & $56.4(36.2)$ & $85.1(23.2)$ & $28.7(4.9)$ & $p<0.0001$ \\
\hline $\begin{array}{l}\text { Patient education from written } \\
\text { pamphlets }(\mathrm{N}=183)\end{array}$ & 37.3 (38.3) & $28.1(34.0)$ & $52.7(40.3)$ & $24.6(5.6)$ & $p<0.0001$ \\
\hline $\begin{array}{l}\text { Fluoride gels/rinses prescribed or } \\
\text { recommended for home use } \\
(\mathrm{N}=183)\end{array}$ & $29.3(32.5)$ & $21.8(27.7)$ & $41.9(36.0)$ & $20.1(4.7)$ & $p<0.0001$ \\
\hline $\begin{array}{l}\text { Patient education from videos or } \\
\text { slides }(\mathrm{N}=182)\end{array}$ & $21.6(35.3)$ & $15.0(28.9)$ & $32.4(41.9)$ & $17.4(5.2)$ & 0.0011 \\
\hline $\begin{array}{l}\text { Intraoral photographs taken } \\
(\mathrm{N}=183)\end{array}$ & $30.3(36.3)$ & $24.0(34.1)$ & $40.8(37.6)$ & $16.9(5.4)$ & 0.0021 \\
\hline $\begin{array}{l}\text { In-office fluoride application } \\
(\mathrm{N}=183)\end{array}$ & $23.3(26.3)$ & $17.2(21.8)$ & $33.4(29.9)$ & $16.2(3.8)$ & $p<0.0001$ \\
\hline Diet counseling $(\mathrm{N}=183)$ & $21.4(27.2)$ & $16.0(24.2)$ & $30.3(29.6)$ & $14.4(4.0)$ & 0.0004 \\
\hline $\begin{array}{l}\text { Oral cancer screening } \\
\text { examination }(\mathrm{N}=182)\end{array}$ & $6.1(21.0)$ & $4.6(17.7)$ & $8.4(25.6)$ & $3.8(3.2)$ & 0.2364 \\
\hline $\begin{array}{l}\text { Blood pressure screening } \\
(\mathrm{N}=183)\end{array}$ & $9.7(20.9)$ & $8.6(19.8)$ & $11.6(22.7)$ & $3.0(3.2)$ & 0.3461 \\
\hline At-home whitening $(\mathrm{N}=183)$ & $4.6(12.6)$ & 3.6 (13.3) & $6.1(11.3)$ & $2.5(1.9)$ & 0.2035 \\
\hline $\begin{array}{l}\text { Intraoral video images taken } \\
(\mathrm{N}=183)\end{array}$ & $3.5(16.2)$ & $2.8(15.6)$ & $4.7(17.3)$ & $1.9(2.5)$ & 0.4538 \\
\hline In-office whitening $(\mathrm{N}=183)$ & $4.4(14.5)$ & $4.3(16.7)$ & $4.5(10.1)$ & $0.2(2.2)$ & 0.9309 \\
\hline
\end{tabular}

this study, which was less when compared with Northern European dentists. A previous study conducted in Norway reported that the mean caries preventive treatment time was $16.6 \%$ of the total treatment time (dentists who did not treat adult patients were excluded $)^{22}$ and $22 \%$ of the total time for child patients. ${ }^{23}$ In Denmark, Iceland and Norway, dental prevention consumes $18-50 \%$ of the dentist's total time in dental care for children and adolescents. ${ }^{24}$ In the USA, the average time that general practitioners spent performing preventive procedures increased from $9.4 \%$ in 1981 to $12.4 \%$ in $1993 .^{25}$ The lower preventive treatment time in Japan may be due to the differences in the healthcare system between Northern Europe and Japan. In Finland in 1999, all inhabitants under the age of 19 were entitled to free comprehensive public dental care, with a utilisation rate of approximately $95 \% .^{26}$ However, in Japan, dental insurance systems mainly cover dental treatment, ${ }^{27}$ so that the percentage of time spent on preventive treatment might be restricted due to economic reasons. In addition, dentists' perception regarding prevention could be one of the reasons that explain variations in preventive practice in this population. Taylor-Gooby et $a l^{28}$ pointed out that professional values for preventive care affect practice patterns of preventive dentistry and that British dentists valued a restorative paradigm as opposed to a preventive paradigm which devalued traditional restorative skills in a context of 'continuing care' payment in 1990s. Also Fox ${ }^{29}$ reviewed dentists' perceptions of prevention and its application in practice and highlighted that recently, most dentists regarded aspects of prevention to be part of their professional work, a source of job satisfaction and of value to the practice, its image and a marker of quality of care. Further studies are needed to clarify associations between dentists' perception of dental prevention and its practice.

A detailed analysis of the practice patterns of prevention-related care revealed that the percentages of time spent on preventive care, which differed between 'more preventive' and 'less preventive' dentists, were significantly different in practices that administered preventive care more than $20 \%$ of the time. Dentists in this study or their dental auxiliaries, provided oral hygiene instruction to $67 \%$ of their patients at some point in the patient's course of treatment and this percentage differed significantly as 'more preventive' and 'less preventive' dentists. The percentage of patients who received hygiene instruction was also associated with the administration of individualised caries prevention in the multiple regression analysis.

Our study clarified that a positive patient perception of preventive dentistry (as measured by the percentage of patients in the practice who are interested in caries prevention) and a higher percentage of patients in the practice who received hygiene instruction were 
Table 5 A multiple logistic regression of whether the dentist provides individualised caries prevention on $50 \%$ or more of patients $(n=163)$

\begin{tabular}{|c|c|c|c|c|}
\hline \multirow{2}{*}{$\frac{\text { Variable }}{\text { Dentists' individual characteristics }}$} & \multirow[t]{2}{*}{ OR } & \multicolumn{2}{|c|}{$95 \% \mathrm{Cl}$} & \multirow[t]{2}{*}{ p Value } \\
\hline & & & & \\
\hline Years since graduation from dental school & 1.00 & 0.95 & 1.06 & 0.883 \\
\hline Gender (reference: male) & 0.39 & 0.09 & 1.69 & 0.211 \\
\hline \multicolumn{5}{|l|}{ Belief about effectiveness of caries risk assessment } \\
\hline Disagree or neutral & 1.00 & & & \\
\hline Agree & 0.91 & 0.31 & 2.67 & 0.865 \\
\hline \multicolumn{5}{|l|}{ Practice setting } \\
\hline \multicolumn{5}{|l|}{ Type of practice } \\
\hline Employed by another dentist & 1.00 & & & \\
\hline Self-employed without partners and without sharing of income, costs or office space & 1.13 & 0.37 & 3.50 & 0.831 \\
\hline \multicolumn{5}{|l|}{ Practice busyness } \\
\hline Too busy to treat all people requesting appointments & 1.00 & & & \\
\hline Provided care to all who requested appointments, but the practice was overburdened & 0.92 & 0.13 & 6.67 & 0.935 \\
\hline $\begin{array}{l}\text { Provided care to all who requested appointments, but the practice was not } \\
\text { overburdened }\end{array}$ & 0.94 & 0.12 & 7.26 & 0.952 \\
\hline Not busy enough—the practice could have treated more patients & 0.64 & 0.06 & 6.49 & 0.706 \\
\hline City population (reference: non-government ordinance designated city) & 1.12 & 0.42 & 2.97 & 0.818 \\
\hline \multicolumn{5}{|l|}{ Patients' characteristics } \\
\hline Percentage of patients interested in caries prevention (every 25\%) & 5.81 & 3.15 & 10.70 & $p<0.0001$ \\
\hline Percentage of child and teenage patients ( $1-18$ years old) & 1.04 & 0.99 & 1.08 & 0.093 \\
\hline Percentage of practice revenue or charges from self-pay & 1.02 & 0.99 & 1.06 & 0.209 \\
\hline \multicolumn{5}{|l|}{ Dental procedure characteristics } \\
\hline $\begin{array}{l}\text { Caries risk assessment is conducted as a routine part of treatment planning } \\
\text { (reference: no) }\end{array}$ & 1.54 & 0.46 & 5.23 & 0.486 \\
\hline Percentage of patients who received hygiene instruction & 1.02 & 1.01 & 1.04 & 0.009 \\
\hline
\end{tabular}

The outcome of interest (individualised caries prevention) was coded as follows: $1=$ provides individualised caries prevention on $50 \%$ or more of the practice's patients; $0=$ does not. Hosmer-Lemshow goodness-of-fit, 0.0503 .

associated with the use of individualised caries prevention to a higher percentage of patients. According to the results of the same questionnaire survey by the US DPBRN, dentists' individual characteristics, practice settings and dental procedures were associated with providing individualised caries prevention to a greater percentage of patients. ${ }^{9}$ Additionally, Brennan and Spencer ${ }^{30}$ noted that dentists' individual characteristics, practice settings and patient characteristics influenced the pattern of preventive care delivered. Our model also included dentists' individual characteristics, practice settings and dental procedures and the dentists' ratings of patients' preference for preventive care were related more strongly than those factors. In addition, a previous systematic review noted that potential barriers to the adherence to physicians' guidelines included dentists' and patients' preferences. ${ }^{31} 32$ As Cabana $e t a \hat{l}^{11}$ noted, potential barriers to the adherence to physicians' guidelines changed depending on the topic and it is possible that dentists' ratings of patient preference are strongly related to the practice of preventive dentistry.

However, our studies suggested that dentists' beliefs about the effectiveness of caries risk assessment were not related to their tendency to use individualised caries prevention. A possible reason for this is that the majority of participants $(67 \%)$ agree that caries risk assessment is effective. This high percentage of agreement with the effectiveness of caries risk assessment is consistent with previous studies. According to the results of the same questionnaire by the US DPBRN, $77 \%$ of dentists answered that they agree with the effectiveness of caries risk assessment. Further studies are needed to clarify the relationship between the use of preventive dentistry and their beliefs about its effectiveness.

The main strength of this study was its relatively wide diversity of participants, with respondents from all seven regions of Japan. The age and gender distribution of this study sample was similar to the actual distribution of dentists in Japan (80\% male, average age in the $40 \mathrm{~s}),^{33}$ thereby enhancing the generalisability of the findings. However, the study results should be approached with caution. First, participants were not selected by random sampling, but rather by responding to the invitation to participate in the JDPBRN. Second, no objective standard for cut-off regarding an adequate prevalence of patients receiving individualised caries prevention has been established, although we used prior planned cut-offs with the mean from the previous US studies. Third, it is possible that the questionnaire's validity is influenced by the reimbursement/insurance system, which is quite different between the USA and Japan. Finally, given the crosssectional nature of our study, causative relationships between factors and the provision of individualised caries prevention were difficult to assess. 


\section{CONCLUSION}

We identified substantial variation in dentists' practice patterns regarding caries preventive dentistry in this study population. Individualised caries prevention was significantly related to provision of other preventive services and to the practice having a higher percentage of patients interested in prevention, but not to the dentist's belief about the effectiveness of caries risk assessment.

Contributors YY, NK, FS, YM, GHG and VVG contributed in arranging reagents/materials/analysis tools, conceived and designed the experiments and revised and reviewed the paper. NK, YM and FS performed the experiments. YY and NK analyzed the data and wrote the paper.

Funding Certain components of this work were supported by the National Institutes of Health grants U01-DE-16746, U01-DE-16747 and U19-DE-22516; a Grant-in-Aid for JSPS Fellows Grant number 23-10883 from the Japan Society for the Promotion of Science (JSPS), Japan.

Competing interests Two authors are dentists employed by a dental clinic (Dr Futoshi Sumida: Mikami Dental and Orthodontics Clinic and Dr Yuki Matsumoto: Matsumoto Dental Clinic).

\section{Patient consent Obtained.}

Ethics approval The Ethics Committee of Kyoto University Graduate School and Faculty of Medicine.

Provenance and peer review Not commissioned; externally peer reviewed.

Data sharing statement The translated version of these questionnaires is available at http://www.dentalpbrn.org/uploadeddocs/Study\%201(Japanese $\%$ 20Version.pdf). (Original English version: http://nationaldentalpbrn.org/pdf/Study \%201\%20questionnaire\%20FINAL\%20after\%20pre-testing\%20021306.pdf).

Open Access This is an Open Access article distributed in accordance with the Creative Commons Attribution Non Commercial (CC BY-NC 3.0) license, which permits others to distribute, remix, adapt, build upon this work noncommercially, and license their derivative works on different terms, provided the original work is properly cited and the use is non-commercial. See: http:// creativecommons.org/licenses/by-nc/3.0/

\section{REFERENCES}

1. Balakrishnan M, Simmonds RS, Tagg JR. Dental caries is a preventable infectious disease. Aust Dent J 2000;45:235-45.

2. Reich E, Lussi A, Newbrun E. Caries-risk assessment. Int Dent J 1999;49:15-26.

3. Rank P, Julien JH, Lyman DO. Preventable dental disease. West $J$ Med 1983;139:545-6.

4. Centers for Disease Control and Prevention. Preventing Dental Caries with Community Programs, 2012. http://www.cdc.gov/ oralhealth/publications/factsheets/dental caries.htm

5. World Health Organization. Oral health. Fact sheet N³18. 2012. http://www.who.int/mediacentre/factsheets/fs318/en/index.htm

6. Zero DT, Fontana M, Martinez-Mier EA, et al. The biology, prevention, diagnosis and treatment of dental caries: scientific advances in the United States. J Am Dent Assoc 2009;140(Suppl 1):25S-34S.

7. Axelsson P, Lindhe J, Nystrom B. On the prevention of caries and periodontal disease. Results of a 15-year longitudinal study in adults. J Clin Periodontol 1991;18:182-9.

8. Axelsson $P$, Nystrom B, Lindhe J. The long-term effect of a plaque control program on tooth mortality, caries and periodontal disease in adults. Results after 30 years of maintenance. J Clin Periodontol 2004;31:749-57.

9. Riley JL 3rd, Gordan VV, Ajmo CT, et al. Dentists' use of caries risk assessment and individualized caries prevention for their adult patients: findings from The Dental Practice-Based Research Network. Community Dent Oral Epidemiol 2011;39:564-73.
10. Fontana M, Zero DT. Assessing patients' caries risk. J Am Dent Assoc 2006;137:1231-9.

11. Twetman S, Fontana M. Patient caries risk assessment. Monogr Oral Sci 2009;21:91-101.

12. Kakudate N, Sumida F, Matsumoto $Y$, et al. Restorative treatment thresholds for proximal caries in dental PBRN. J Dent Res 2012;91:1202-8.

13. Yokoyama Y, Kakudate N, Sumida F, et al. Dentists' dietary perception and practice patterns in a dental practice-based research network. PLOS ONE 2013;8:e59615.

14. Gilbert GH, Williams OD, Rindal DB, et al. The creation and development of the dental practice-based research network. J Am Dent Assoc 2008;139:74-81.

15. Gordan VV, Garvan CW, Heft MW, et al. Restorative treatment thresholds for interproximal primary caries based on radiographic images: findings from the Dental Practice-Based Research Network. Gen Dent 2009;57:654-63; quiz 64-6, 595, 680.

16. Makhija SK, Gilbert GH, Rindal DB, et al. Dentists in practice-based research networks have much in common with dentists at large: evidence from the Dental Practice-Based Research Network. Gen Dent 2009;57:270-5.

17. Sperber AD. Translation and validation of study instruments for cross-cultural research. Gastroenterology 2004;126(1 Suppl 1): S124-8.

18. Gordan VV, Bader JD, Garvan CW, et al. Restorative treatment thresholds for occlusal primary caries among dentists in the dental practice-based research network. J Am Dent Assoc 2010;141:171-84.

19. Bader JD, Shugars DA. What do we know about how dentists make caries-related treatment decisions?. Community Dent Oral Epidemiol 1997;25:97-103.

20. Gilbert GH, Shewchuk RM, Litaker MS. Effect of dental practice characteristics on racial disparities in patient-specific tooth loss. Med Care 2006;44:414-20.

21. Gordan VV, Riley JL III, Carvalho RM, et al. Methods used by Dental Practice-based Research Network (DPBRN) dentists to diagnose dental caries. Oper Dent 2011;36:2-11.

22. Haugejorden $O$, Nielsen WA. Experimental study of two methods of data collection by questionnaire. Community Dent Oral Epidemiol 1987;15:205-8.

23. Wang NJ, Aspelund GO. Preventive care and recall intervals. Targeting of services in child dental care in Norway. Community Dent Health 2010;27:5-11.

24. Wang NJ, Kalletstal C, Petersen PE, et al. Caries preventive services for children and adolescents in Denmark, Iceland, Norway and Sweden: strategies and resource allocation. Community Dent Oral Epidemiol 1998;26:263-71.

25. Brown LJ, Lazar V. Dental procedure fees 1975 through 1995: how much have they changed? J Am Dent Assoc 1998; 129:1291-5.

26. Helminen SK, Vehkalahti MM. Does caries prevention correspond to caries status and orthodontic care in 0- to 18-year-olds in the free public dental service? Acta Odontol Scand 2003;61: 29-33.

27. Miyazaki $\mathrm{H}$, Morimoto $\mathrm{M}$. Changes in caries prevalence in Japan Eur J Oral Sci 1996;104(4 (Pt 2)):452-8.

28. Taylor-Gooby $\mathrm{P}$, Sylvester S, Calnan M, et al. Knaves and gnashers: professional values and private dentistry. J Soc Policy 2000;29:375-95.

29. Fox C. Evidence summary: what do dentists mean by 'prevention' when applied to what they do in their practices? Br Dent $J$ 2010;208:359-63.

30. Brennan DS, Spencer AJ. The role of dentist, practice and patient factors in the provision of dental services. Community Dent Oral Epidemiol 2005;33:181-95.

31. Cabana MD, Rand CS, Powe NR, et al. Why don't physicians follow clinical practice guidelines? A framework for improvement. JAMA 1999;282:1458-65.

32. Cochrane LJ, Olson CA, Murray S, et al. Gaps between knowing and doing: understanding and assessing the barriers to optimal health care. J Contin Educ Health Prof 2007;27:94-102.

33. Ministry of Health Labour and Welfare. Survey of Physicians, Dentists and Pharmacists: trends in the number of dentists. 2010. http://www.mhlw.go.jp/toukei/saikin/hw/ishi/10/dl/ kekka_2.pdf 